\title{
CAPTURE
}

\section{CREATIVE DIRECTION OF IKA MAHARDIKA IN THE PREPRODUCTION OF THE UNREMEMBERED DOCUMENTARY FILM}

\author{
St. Hadidja Syam ${ }^{1}$, Damar Tri Afrianto ${ }^{2}$, dan Sri Wastiwi $\mathbf{S}^{3}$ \\ ${ }^{1}$ Institut Seni dan Budaya Indonesia (ISBI) Sulawesi Selatan \\ ${ }^{2}$ Institut Seni dan Budaya Indonesia (ISBI) Sulawesi Selatan \\ ${ }^{3}$ Institut Seni dan Budaya Indonesia (ISBI) Sulawesi Selatan \\ E-mail: khadidjasyams04@gmail.com
}

\begin{abstract}
This study aims to describe Ika Mahardika's creative process in directing the documentary film The Unremembered, especially in the preproduction stage. The research method uses descriptive qualitative. The results showed that director Ika Mahardika's creativity in digging data about Salawati Daud lies in the ability to use ethnographic research methods in a coherent manner starting from literature search, field observations, interviews and documents. In addition, Ika Mahardika's creativity also lies in data processing starting from selecting data with consideration of the capacity of the information provided then how the data is displayed chronologically.
\end{abstract}

Keywords: Creative procces, directing, Ika Mahardika, The Unremembered, preproduction

\section{ABSTRAK}

Penelitian ini bertujuan untuk mendeskripsikan proses kreatif lka Mahardika dalam menyutradarai film dokumenter The Unremembered khususnya pada tahapan praproduksi. Metode penelitian menggunakan deskriptif kualitatif. Hasil penelitian menunjukkan bahwa kreativitas sutradara Ika Mahardika dalam menggali data mengenai Salawati Daud terletak pada kemampuan penggunaan metode riset etnografi secara runtut mulai dari penelusuran literatur, observasi lapangan, wawancara dan dokumen. Selain itu, kreativitas Ika Mahardika juga terletak pada pengolahan data mulai dari penyeleksian data dengan pertimbangan kapasitas informasi yang diberikan kemudian bagaimana data itu ditampilkan secara kronologis.

Kata kunci: Proses kreatif, penyutradaraan, Ika Mahardika, The Unremembered, praproduksi.

\section{PENDAHULUAN}

Sejarah merupakan ilmu yang penting untuk diketahui dan dipahami oleh generasi penerus bangsa. Dalam mengolah atau mencari peristiwa-peristiwa sejarah dapat dilakukan dengan berbagai media seperti buku, literatur, dan film. Dewasa ini film menjadi salah satu media yang sering digunakan untuk menarasikan sebuah peristiwa atau sejarah karena dianggap tepat sebagai sumber pengetahuan masa lampau. Film dalam hal ini bukan hanya sekedar tontonan yang tujuannya sebatas sebagai hiburan akan tetapi mampu memperkaya persepsi seperti yang dijelaskan Bazin: film is not only entertainment but film is in art of processing and intensifying our perception 
of reality (Afrianto, 2019).

Jenis film yang mampu untuk mengolah atau mengungkapkan sejarah salah satunya adalah jenis film dokumenter. Film dokumenter merupakan karya film berdasarkan realita atau fakta perihal pengalaman hidup seseorang atau mengenai peristiwa. Film dokumenter juga memiliki berbagai bentuk, salah satu diantaranya adalah bentuk biografi atau potret. Film dokumenter biografi merupakan representasi kisah pengalaman hidup seorang tokoh yang terkenal ataupun anggota masyarakat biasa yang riwayat hidupnya dianggap hebat, menarik, unik, atau menyedihkan. Bentuk biografi atau potret ini umumnya berkaitan dengan aspek human interest, sementara isi tuturan bias berupa kritik, penghormatan, atau simpati (Ayawalia, 2008).

Salah satu film yang menggunakan jenis dokumenter biografi adalah The Unremembered karya sutradara Ika Mahardika. Film ini merupakan film dokumenter yang mengangkat sosok Salawati Daud yang merupakan seorang tokoh pergerakan nasional dari Sulawesi yang pernah menjabat sebagai salah satu walikota Makassar yang dalam pengertian pada masa itu adalah primus interpares ${ }^{1}$ pada tahun 1949. Sosok perempuan sederhana ini dulunya merupakan seorang

1 Primus Interpares adalah sistem pemilihan pemimpin pada awal setelah kemerdekaan. guru di daerah Tomohon ${ }^{2}$ dan juga berperan aktif di dunia jurnalistik pada tahun 1930-an. Sebagai seorang aktivis perempuan, Salawati Daud kerap terlibat di bidang politik, emansipasi perempuan dan pendidikan di masa sebelum kemerdekaan dan pasca kemerdekaan. Pada tahun 1950-an Salawati Daud terlibat dalam pembentukan serta aktif dalam organisasi gerakan wanita (GERWANI), Salawati Daud berhasil melenggang ke parlemen sebagai anggota Partai Komunis Indonesia pada masa orde lama. Namun, pada masa Orde Baru sosok dan identitas Salawati Daud dihilangkan dari sejarah.

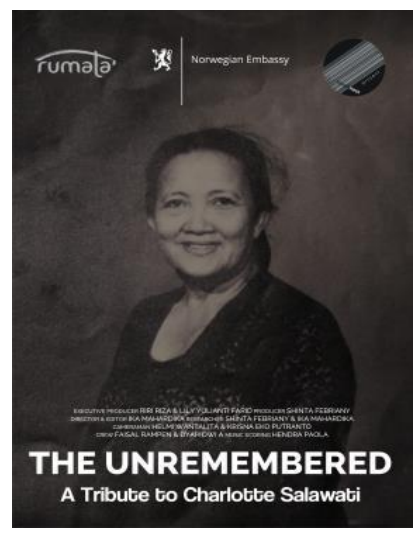

Gbr 1. Poster film The Unremembered (Sumber: Ika Mahardika, 2019)

Ika Mahardika memilih mengangkat sosok Salawati Daud berlandaskan keprihatinannya terhadap Salawati Daud. Sebagai pahlawan kemerdekaan dan tokoh pergerakan nasional, Salawati Daud tidak terlalu dianggap keberadaannya, bahkan jejak arsipnya di Kota Makassar tidak ada, sehingga Ika Mahardika

2 Tomohon adalah nama salah satu daerah yang ada di Sulawesi Utara 
berusaha mengeksplorasi sejarah Salawati Daud ini dalam bentuk film. Film dokumenter The Unremembered dibuat pada tahun 2018 dan diproduksi oleh Loneliness Project. Film ini pertama kali diputar di malam pembukaan Makassar International Writers Festival pada tanggal 2 Mei 2018 dan pernah diputar di beberapa tempat lainnya seperti di festival kesenian di Yogyakarta, University of London, dan Universitas Melbourne Australia.

Selaku sutradara, Ika Mahardika memiliki andil yang besar dalam menciptakan gagasan melalui proses kreatif yang dilakukan. Proses kreatif yang dilakukan dapat diteliti untuk melihat cara kerja Ika Mahardika dalam membuat film dokumenter The Unremembered. Tahaptahap membuat film dokumenter menurut Gerzon Ayawalia dalam bukunya yang berjudul Dari Ide Sampai Produksi terdiri dari praproduksi, produksi, dan pascaproduksi. Penelitian ini menitikberatkan pada tahap praproduksi, dengan pertimbangn bahwa lka Mahardika memiliki kelebihan dalam menggali dan mengolah data mengenai Salawati Daud secara kompleks mulai dari perjalanannya menjadi aktivis perempuan hingga menjadi tokoh pergerakan nasional. Film dokumenter The Unremembered ini memiliki kekuatan menampilkan data-data sejarah Salawati Daud di setiap scenenya. Data-data yang ditampilkan dalam

film dokumenter The Unremembered mengenai Salawati Daud memiliki tingkat akurasi dan kevalidan data yang cukup baik. Hal ini dapat dilihat dari scene-scene yang memuat sumber data dokumendokumen dari riset, narasumber sejarah yang kompeten di bidangnya hingga penelusuran pada keluarga-keluarga terdekatnya. Proses kreatif yang dilakukan oleh Ika Mahardika sebagai sutradara film dokumenter The Unremembered menarik untuk dikaji, khususnya pada tahapan praproduksi, karena hal ini menjadi sangat penting dalam menentukan keberhasilan filmnya. Dari uraian tersebut, muncul sebuah rumusan masalah bagaimana proses kreatif penyutradaraan Ika Mahardika dalam film dokumenter The Unremembered pada tahapan praproduksi.

\section{TINJAUAN PUSTAKA}

Terdapat beberapa penelitian
terdahulu yang dijadikan sebagai
pembanding dengan penelitian ini agar
tidak terjadi penjiplakan karya, diantaranya:
Penelitian berjudul Proses Kreatif Eddie
Cahyono dalam Penciptaan Film Siti yang
ditulis oleh Widhi Nugroho, Titus Soepono
Adji, dan Sri Wastiwi Setiawati yang
diterbitkan dalam Jurnal Capture Vol.08
No.02 tahun 2017. Penelitian ini mengkaji
mengenai proses kreatif dari Eddie
Cahyono selaku sutradara yang
merangkap sebagai penulis skenario dalam
film Siti. Fokus penelitian, mengkaji proses


kreatif Eddie Cahyono dalam mencipta film Siti dengan biaya produksi yang rendah. Berdasarkan hasil analisis penelitian tersebut tampak bahwa proses kreatif Eddie Cahyono dalam menulis skenario mencangkup pencarian ide, tema, setting cerita, konflik hingga elemen pembentuk skenario secara utuh. Sedangkan proses kreatif Eddie Cahyono sebagai sutradara, melalui tahapan praproduksi (breakdown naskah, casting, reading, rehearsal), produksi (pengambilan gambar di lapangan) dan pascaproduksi (editing) dengan pendekatan mise-en-scene. Perbedaan secara mendasar adalah Widhi Nugroho, Titus Soepono Adji, dan Sri Wastiwi Setiawati membahas tentang proses krearif Eddie Cahyono dalam penciptaan film Siti, sedangkan penelitian ini membahas tentang proses kreatif penyutradaraan Ika Mahardika dalam film dokumenter The Unremembered.

$$
\text { Penelitian berjudul Gaya }
$$

Dokumenter dalam Film Renita, Renita Karya Sutradara Tonny Trimarsanto yang ditulis oleh Helmy Yunica Andrean (2018) Prodi Televisi dan Film FSRD Institut Seni Indonesia Surakarta. Penelitian ini meneliti tentang gaya dokumenter yang digunakan dalam film Renita, Renita dengan menggunakan batasan-batasan pada film dokumenter. Dalam penelitiannya, Helmy Yunica Andrean menyimpulkan bahwa film Renita, Renita menggunakan campuran beberapa gaya dokumenter yaitu gaya observasional, ekpositori dan reflexive. Penggunaan beberapa gaya di dalam film membuat film Renita, Renita memiliki ciri khas di bagian gaya yaitu terobosan gayagaya yang dipadukan. Pada film ini, tidak hanya satu gaya saja yang muncul, melainkan ada beberapa gaya yang dapat memberi warna baru film dokumenter di dalam proses menyampaikan pesan kepada penonton. Perbedaan penelitian ini adalah Helmy Yunica Andrean menggunakan 7 batasan-batasan dokumenter sebagai kunci untuk mencari gaya pada film dokumenter Renita, Renita, sedangkan dalam penelitian ini membahas tentang proses kreatif penyutradaraan lka Mahardika dalam film dokumenter The Unremembered.

Penelitian berjudul Proses Kreatif Sutradara dalam Pembuatan Film Musikal Anak Rena Asih yang ditulis oleh Rizka Febry Indriani (2018) Prodi Televisi dan Film FSRD Institut Seni Indonesia Surakarta. Penelitian ini meneliti tentang proses kreatif sutradara pembuatan film musikal anak Rena Asih dengan menggunakan unsur naratif dan sinematik. Pada penelitian Rizka Febry indriani mengkaji proses kreatif sutradara melalui tiga tahap yakni praproduksi, produksi, dan pascaproduksi. Rizka Febry Indriani menyimpulkan hasil penelitiannya bahwa kreativitas sutradara menghadirkan film Rena Asih dengan menonjolkan lokalitas Jawa Timur, mulai dari pemilihan judul, 


\section{CAPTURE}

bahasa, setting cerita, musik, dan semua aspek yang ada dalam film. Sutradara juga memiliki formulasi khusus dalam pembuatan film musikal yang terletak pada bagian plotting adegan, sutradara memilih adegan-adegan yang tensinya bisa dinaikkan melalui musikal. Setelah itu, naskah yang awalnya berbentuk 143 naskah film fiksi biasa diubah bentuknya ke dalam naskah film musikal dengan menyisipkan lirik lagu yang sudah dibuat dengan pertimbangan suasana adegan yang ada pada naskah. Perbedaan mendasar dengan penelitian ini adalah Rizka Febry Indriani membahas tentang proses kreatif sutradara dalam film musikal anak Rena Asih, sedangkan dalam penelitian ini membahas tentang bagaimana proses kreatif penyutradaraan Ika Mahardika dalam film dokumenter The Unremembered pada tahapan praproduksi.

Penelitian berjudul Strategi BW Purba dalam Casting dan Directing Tokoh Mbah Sri pada Film Ziarah yang ditulis oleh Muna Rif'atil Akhlaq dan Sri Wastiwi Setiawati yang diterbitkan dalam Jurnal Capture Vol.10 No.01 tahun 2018. Fokus penelitian ini mengkaji strategi yang dilakukan oleh BW Purba Negara dalam proses casting dan directing tokoh Mbah Sri yang diperankan oleh Mbah Panco Sutiyem yang berusia 95 tahun. Hasil dari penelitian ini menunjukkan bahwa BW Purba selaku sutradara telah berhasil memanipulasi keterbatasan dan kekurangan Mbah Ponco melalui strategi dalam casting dan directing. Casting dilakukan dengan cara mendatangi satu per satu (door to door) nenek-nenek yang telah berusia 90 -an tahun, dengan catatan kondisi fisiknya masih kuat dan bersedia untuk diajak bermain film serta sesuai dengan 3D karakter Mbah Sri, sedangkan pada proses directing BW Purba memilih untuk menggali potensi pengalaman Mbah Ponco pada saat Agresi Militer II, kemudian dilakukan revisi skenario mengikuti cerita Mbah Ponco, khususnya yang berkaitan dengan ingatan pada masa perang yang dialami Mbah Ponco. Perbedaan mendasar dengan penelitian ini adalah Muna Rif'atil Akhlaq membahas tentang strategi yang dilakukan oleh BW Purba dalam casting dan directing tokoh Mbah Sri pada film Ziarah, sedangkan penelitian ini membahas tentang bagaimana proses kreatif penyutradaraan Ika Mahardika dalam film dokumenter The Unremembered khususnya pada tahapan praproduksi.

\section{METODE}

Jenis penelitian yang mengkaji proses kreatif Ika Mahardika dalam film The Unremembered ini adalah penelitian kualitatif, yang disajikan secara deskriptif. Penelitian kualitatif yang dilakukan tidak semata-mata mendeskripsikan, tetapi yang lebih penting adalah menemukan makna yang terkandung di baliknya dengan didukung oleh catatan yang mendalam 
terhadap proses yang dilakukan Ika Mahardika pada tahap praproduksi film The Unremembered. Penemuan makna tersebut, sebagaimana pendapat yang mengatakan bahwa sebuah film dokumenter secara esensial akan menunjukkan sebuah nilai atau makna dan sesuatu yang nyata atau faktual (Candra D.A., 2013).

Sumber data penelitian berupa data primer dan data sekunder. Sumber data primer adalah proses kreatif Ika Mahardika dalam menyutradarai film The Unremembered. Data diperoleh melalui hasil interview atau wawancara dengan lka Mahardika selaku sutradara dan Shinta Febrianty selaku produser film The Unremembered. Narasumber lain juga dari pihak pelaku atau yang terlibat pembuatan film The Unremembered.

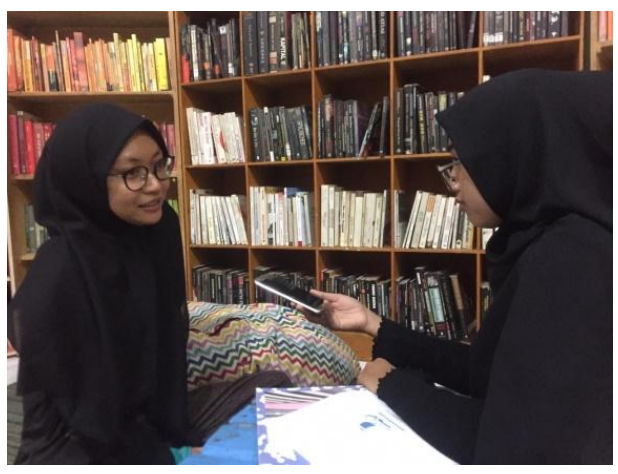

Gambar 2. Wawancara dengan Ika Mahardika (Foto: Muh. Sabri, 2019)

Data sekunder dalam penelitian ini berupa film. Data diperoleh melalui film The Unremembered yang didapatkan dari Ika Mahardika dalam bentuk soft file pada tanggal 11 Mei 2019. Data ini digunakan untuk memvalidasi hasil wawancara yang sudah dilakukan. Data sekunder dimaksudkan untuk melengkapi data dan sebagai pendukung data.

Pengumpulan data dilakukan dengan observasi, wawancara, dan studi pustaka. Wawancara dengan lka Mahardika dan Shinta Febriany untuk menggali data penelitian seputar proses kreatif yang dilakukan pada tahapan praproduksi film The Unremembered. Observasi dilakukan dengan melihat dan mengamati behind the scene film tersebut. Analisis data diarahkan untuk menjawab permasalahan dalam penelitian, bagaimana proses kreatif penyutradaraan Ika Mahardika dalam film dokumenter The Unremembered pada tahapan praproduksi.

\section{PEMBAHASAN}

Film The Unremembered merupakan karya film dokumenter pertama dari Ika Mahardika. Sebelumnya, Ika Mahardika menyutradarai film fiksi pendek dan menjadi penulis naskah di beberapa film. Di dalam film dokumenter The Unremembered, Ika Mahardika berperan sebagai sutradara, researcher, dan editor. Ika Mahardika dibantu oleh Sinta Febriany yang juga berperan sebagai produser sekaligus researcher.

Film The Unremembered juga merupakan wujud dari penerjemahan ideide kreatif sutradara. Film dokumenter ini mengangkat sosok Salawati Daud yang merupakan tokoh penting di Sulawesi Selatan yang jejak-jejaknya telah 


\section{CAPTURE}

dihilangkan dari sejarah. Film ini mampu menghadirkan ingatan-ingatan sejarah mengenai Salawati Daud yang mulai terlupakan. Kekuatan data tentang Salawati Daud menjadi daya tarik tersendiri dari film ini.

Kesuksesan film The

Unremembered tidak lepas dari proses kreatif yang dilakukan oleh Ika Mahardika dalam penciptaan film ini. Pencarian data (riset) menjadikan film ini mampu mengungkap jejak-jejak Salawati Daud dengan cukup kompleks. Proses tahapantahapan tersebut dilakukan Ika Mahardika sebelum memproduksi film (praproduksi).

\subsection{Penentuan Subjek Film Dokumenter}

\section{The Unremembered}

Tahapan kreasi dalam pembuatan film The Unremembered dimulai dari penemuan ide dan perumusan konsep.

\section{1) Menemukan Ide}

Praproduksi dalam film dokumenter

The Unremembered berjalan selama hampir satu setengah bulan. Namun jauh sebelum Sinta Febriany, selaku produser film ini, menggandeng Ika Mahardika menjadi sutradara, ia telah mengamati Salawati Daud yang menjadi objek riset selama dua bulan lebih, hingga praproduksi film dokumenter the Unremembered berjalan hampir lima bulan. Penemuan ide untuk penggarapan film The Unremembered ini dimotivasi oleh produser yakni Shinta Febriany. Shinta Febriany yang bekerja sama dengan
Makassar International Writers Festival menggandeng Ika Mahardika, setelah Shinta menemukan ide untuk membuat film dokumenter.

Pertemuan gagasan Shinta Febriany selaku produser mengenai Salawati Daud ini berawal dari penelitiannya tentang tokoh-tokoh perempuan penting di Sulawesi Selatan. Salah satu yang menarik perhatiannya adalah Salawati Daud. Shinta Febriany sangat tertarik dengan Salawati Daud karena Salawati adalah seorang aktivis perempuan dan penggagas persatuan Indonesia, dia juga merupakan seorang jurnalis, juga pejabat penting di Sulawesi Selatan yang pemikiran atau gagasan-gagasannya tentang perempuan dan kepemimpinan masih relevan digunakan hingga saat ini.

Melihat betapa minimnya data mengenai Salawati Daud ini membuat Sinta Febriany terpacu untuk membagikan kisah perjuangan Salawati Daud tersebut kepada penonton, untuk itu diperlukan sebuah media yang dapat menjelaskan secara jelas dan singkat. Film dianggap media yang paling tepat karena film memenuhi kriteria tersebut, dapat menjelaskan cerita secara jelas dengan singkat. Selain itu, film dirasa paling mampu untuk mengambil hati kawan muda. Oleh karena itu Shinta Febriany menggandeng Ika Mahardika sebagai sutradara, salah satu pertimbangannya adalah gender. Menurutnya, membuat film 
dokumenter tentang tokoh perempuan akan lebih baik jika menggunakan sudut pandang perempuan. Berikut adalah kutipan yang memperlihatkan terbentuknya ide dalam pembuatan film ini:

"Ketika ada ide Salawati ini dibikinkan film dokumenter supaya bisa lebih menggait, mengambil hati kawan-kawan muda, biasanya kan lebih mudah kalo lewat film gitu, nah saya kepikir mau mengajak siapa nah ketika itu lka kebetulan salah satu yang ikut di program Makassar In Cinema dimana saya menjadi salah satu pengajarnya nah saya pikir mungkin kalau perempuan menggunakan sudut pandang perempuan mungkin oke juga, jadi ketika itu saya mengajak lka untuk ikut riset" (Febrianty, 2019).

Film The Unremembered ini juga dibuat sebagai salah satu publikasi dari Makassar International Writers Festival (MIWF). MIWF memiliki projek film dokumenter setiap tahunnya. Ika Mahardika selaku sutradara merasa tertarik untuk menggarap produksi dokumenter ini karena menurutnya Salawati Daud adalah salah satu pejuang perempuan yang melawan ketidakadilan pemerintahan Hindia Belanda selama pemerintahan Orde Baru, yang namanya seakan tenggelam dan terlupakan dalam jejak sejarah, sehingga Ika Mahardika berusaha mencatatnya kembali dalam bentuk film. Berikut adalah petikan wawancara Ika Mahardika :

"Salawati Daud memiliki kesadaran yang cukup tinggi mengenai kemampuan pergerakan

\begin{abstract}
perempuan, sehingga Salawati Daud berusaha untuk mendiplomasi kaum-kaum perempuan agar ikut membantu kaum lelaki memperjuangkan kemerdekaan Indonesia. Saya sangat merasa ironis, sebagai pahlawan kemerdekaan Salawati Daud ini tidak terlalu dikenal keberadaannya, bahkan arsipnya tidak terlalu banyak. Saya ingin mengeksplorasi pemikiranpemikiran Salawati Daud yang masih relevan digunakan hingga sekarang. Pembuatan film ini juga sebenarnya adalah salah satu usaha untuk mencatat Salawati Daud kembali dalam sejarah dalam bentuk film." (Mahardika, 2019).
\end{abstract}

\section{2) Merumuskan Konsep}

Film The Unremembered ini dikemas dalam bentuk dokumenter, selain karena merupakan projek tahunan Makassar Internasional Writers Festival, Ika Mahardika juga ingin menampilkan kesan realitas yang dibangun dalam film ini karena informasi yang ingin disampaikan adalah informasi yang konkrit, informasi tentang tokoh penting di Sulawesi Selatan.

Dokumenter The Unremembered ini berbentuk potret atau lebih dikenal dengan biografi. Bentuk ini merupakan representasi kisah pengalaman hidup seorang tokoh terkenal ataupun anggota masyarakat biasa yang riwayat hidupnya dianggap menarik, unik, atau menyedihkan. Film The Unremembered ini menceritakan seorang tokoh yakni Salawati Daud. Bentuk biografi dipilih karena bentuk ini dianggap lebih informatif untuk menyampaikan kedalaman 


\section{CAPTURE}

personality Salawati Daud sehingga akan lebih mudah untuk dipahami penonton.

Selain bentuk biografi, gaya juga merupakan hal yang penting untuk dipikirkan pada saat praproduksi, hal ini dikarenakan gaya sebuah film mampu mengarahkan penontonnya. Lewat gaya pembuat film dokumenter dapat mengkonstruksi cerita yang akan dibentuk menuju ke arah mana. Ika mahardika memilih gaya Ekspositoris dalam pembuatan film ini karena ingin menampilkan pesannya secara langsung kepada penonton, sehingga pesan yang disampaikan mengenai sosok Salawati Daud akan sama dan tidak ada perbedaan penafsiran atau multitafsir. Sesuai dengan ciri dari gaya Ekpositoris yaitu adanya petikan wawancara narasumber, Ika Mahardika merasa bahwa pemilihan gaya Ekspositoris ini akan lebih mempermudah penonton mendalami isi film.

Film The Unremembered ini memiliki bentuk biografi atau potret dengan gaya Ekspositoris. Dua hal mendasar ini kemudian diterapkan ke dalam proses pembuatan film The Unremembered ini.

\subsection{Metode Riset}

Langkah yang dilakukan Ika Mahardika dan Shinta Febriany setelah menentukan tema dan konsep pembuatan film dokumenter The Unremembered ini adalah riset mengenai subjek. Sepanjang proses pembuatan film, tahapan riset sangat mendominasi, mengingat film ini memiliki kesadaran riset yang cukup tinggi. Riset sangat dibutuhkan sebelum dokumenter diproduksi. Riset yang dimaksudkan adalah mengumpulkan data atau informasi melalui observasi mendalam mengenai subjek, peristiwa, dan lokasi sesuai tema yang akan diketengahkan.

Ika Mahardika dan Shinta Febriany melakukan pencarian data dengan melakukan pendekatan ke sumber informasi yang berada di beberapa daerah di luar kota Makassar. Pendekatan riset yang digunakan dalam proses pencarian data adalah metode Etnografi. Penelitian etnografi adalah kegiatan pengumpulan bahan keterangan atau data yang dilakukan secara sistematik mengenai cara hidup serta berbagai aktivitas sosial dari suatu masyarakat dengan tujuan untuk menguraikan informasi secara holistik. Ika Mahardika dan Shinta Febriany menerapkan pendekatan Etnografi ini dengan cara mengunjungi kediaman Salawati Daud dan melakukan wawancara dengan keluarga Salawati Daud. Selain untuk memverifikasi data yang telah didapatkan sebelumnya, hal ini juga merupakan upaya Ika Mahardika dan Shinta Febriany mendekatkan diri ke sumber informasi. Seperti yang digambarkan Shinta febrianty dalam wawancaranya:

"Sebenarnya risetnya itu lebih ke etnografi. Jadi kita selain cari data- 
data dari berbagai perpustakaan, dari internet, kita juga berupaya menjumpai atau berkunjung ke rumahnya yang dulu, ketemu dengan cucunya, ketemu dengan cicitnya, terus wawancara dengan keduanya di Jakarta ketika itu, terus berkunjung ke makamnya juga, ya metodenya sebenarnya lebih ke upaya mendekatkan diri ke sumber informasinya seperti itu." (Febrianty, 2019).

Proses pencarian data dalam film dokumenter The Unremembered ini dimulai dari studi pustaka berupa bukubuku dan literatur-literatur yang ditemukan Ika Mahardika di internet. Setelah itu Ika melakukan diskusi bersama dengan teman-teman pustakawannya di Kata Kerja. Setelah mendapatkan informasi dari teman- teman pustakawan, Ika Mahardika kemudian mencari sebuah tesis yang ditulis oleh Siti Maryam yang kemudian menjadi sumber informasinya tentang Salawati Daud. Berangkat dari tesis yang berjudul Salawati Daud dan Gagasan tentang Persatuan Nasional Indonesia Sebuah Biografi Politik 1909-1985 tersebut Ika Mahardika kemudian mencatat hal-hal yang menurutnya penting kemudian menelusuri jejak-jejak Salawati Daud di kota Makassar. Berikut metode riset dengan pendekatan Etnografi yang dilakukan Ika Mahardika dalam proses pencarian data mengenai Salawati Daud:

\section{1) Studi Literatur}

Pelacakan jejak-jejak Salawati Daud, Ika Mahardika terlebih dahulu melakukan pencarian di internet mengenai
Salawati Daud, namun data yang ditemukan tidak lengkap dan sumbernya tidak jelas, maka Ika Mahardika kemudian membaca beberapa buku yang beberapa halaman di dalamnya menyebutkan nama Salawati Daud. Di dalam konteks film dokumenter, studi literarur digunakan Ika Mahardika sebagai penuntun untuk masuk ke dalam permasalahan yang sedang diteliti. Buku-buku tersebut diantaranya: Buku berjudul Politik dan Postkolonialisme di Indonesia oleh Budi Susanto yang diterbitkan oleh Kansius tahun 2003 di Yogyakarta. Berdasarkan buku tersebut, Ika Mahardika kemudian mengetahui bagaimana perjalanan politik Salawati Daud. Pengetahuan yang Ika Mahardika peroleh kemudian dituangkan ke dalam tulisan-tulisan dalam catatan kecil untuk menjadi landasan dasar dalam menelisik jejak-jejak Salawati Daud selanjutnya.

Buku berjudul Penghancuran Gerakan Perempuan, Politik Seksual di Indonesia Pasca Kejatuhan PKI yang ditulis oleh Saskia E.Wieringa dan diterbitkan oleh Galang Press pada tahun 2010 di Yogyakarta. Setelah membaca buku ini Ika Mahardika kemudian banyak mengetahui tentang GERWANI dan hubungannya dengan PKI. Dari buku ini Ika Mahardika juga mengetahui bagaimana kedudukan Salawati Daud dalam GERWANI.

Tesis berjudul "Salawati Daud dan Gagasan tentang Persatuan Nasional 


\section{CAPTURE}

Indonesia Sebuah Biografi Politik 19091985" yang ditulis oleh Siti Maryam, Universitas Gajah Mada, pada tahun 2014. Hasil pembacaan Ika Mahardika terhadap tesis ini didapatkan pemahaman tentang silsilah keluarga Salawati Daud beserta alamatnya, dan hal itu menuntun Ika dalam mencari jejak-jejak Salawati Daud di kota Makassar hingga ke Jakarta.

\section{2) Observasi}

Observasi yang dilakukan oleh Ika Mahardika dalam rangka pencarian data melalui tempat-tempat yang dianggap memiliki keterkaitan dengan Salawati Daud seperti Museum Kota Makassar, Badan Arsip, Balai Pelestarian Nilai Budaya, Perpustakaan Daerah, dan Universitas Hasanuddin, yang dapat dijabarkan sebagai berikut:

a) Museum Kota Makassar

Lokasi yang pertama kali dikunjungi oleh Ika Mahardika adalah Museum Kota Makassar, menurut Ika Mahardika bahwa fakta terbesar tentang Salawati Daud adalah dia pernah menjabat sebagai Walikota perempuan pertama di Makassar dan juga Indonesia. Namun pada akhirnya Ika Mahardika tidak dapat melacak jejakjejak Salawati Daud mengenai kepemimpinannya sebagai walikota di Museum Kota Makassar (Mahardika, 2019).

b) Badan Arsip

Setelah museum, Ika Mahardika kemudian beranjak ke Badan Arsip di
Jalan Perintis Kemerdekaan Makassar dengan tujuan untuk mencari arsip-arsip mengenai Salawati Daud yang pernah menjadi tahanan polistik di Masamba karena keterlibatannya dalam kasus Kahar Muzakkar. Namun pada akhirnya Ika Mahardika tidak dapat berhasil melacak arsip-arsip Salawati Daud mengenai pembebasan penahanannya.

c) Perpustakaan Daerah

Pada tanggal 23 Maret 2018, Ika Mahardika menuju ke Perpustakaan Daerah di Jalan Alauddin Kota Makassar. Di sana Ika Mahardika mencari literaturliteratur tentang biografi Salawati Daud, namun sayangnya tidak ada satupun buku yang menjelaskan tentang Salawati Daud di dalamnya, yang Ika Mahardika temukan kebanyakan adalah tokoh-tokoh atau pahlawan-pahlawan yang bergerak di bidang militer bukan diplomatik.

d) Balai Pelesatarian Nilai Budaya (BPNB)

Lokasi berikutnya yang dicari lka Mahardika yakni Balai Pelestarian Nilai Budaya (BPNB) yang lokasinya tidak jauh dari Perpustakaan Daerah Makassar. Karena merasa informasi yang lka Mahardika dapatkan belum cukup akhirnya Ika Mahardika kemudian menelaah kembali mengenai lokasi-lokasi yang memungkinkan adanya jejak Salawati Daud (Mahardika, 2019).

e) Universitas Hasanuddin (UNHAS)

Pada tanggal 13 April 2018, Ika Mahardika datang ke Universitas 
Hasanuddin Makassar. Ika Mahardika kemudian menemui Dias Pradadimara yang berasal dari Jawa, salah satu dosen program studi sejarah di universitas tersebut yang juga merupakan seorang peneliti dan melakukan wawancara terkait Salawati Daud.

Setelah melihat teknik-teknik observasi yang dilakukan Ika Mahardika dalam melacak jejak-jejak Salawati Daud dengan mendatangi tempat-tempat yang telah ditentukan sebelumnya, maka dapat dikemukakan bahwa teknik observasi Ika Mahardika ini berbentuk observasi terkendali. Observasi terkendali merupakan observasi yang tidak melibatkan hubungan emosi atau perasaan antara peneliti dengan sasaran yang ditelitinya. Pada observasi terkendali ini para pelaku yang akan diamati, dipilih, dan kondisi-kondisi yang ada dalam ruang atau tempat kegiatan dikendalikan oleh peneliti (Rohendi Rohidi, 2011). Tujuan penggunaan observasi terkendali ini dimaksudkan agar pencarian data-data mengenai Salawati Daud dapat lebih spesifik.

\section{3) Wawancara}

Tahapan riset selanjutnya yang dilakukan Ika Mahardika adalah wawanacara. Ika Mahardika melakukan wawancara dengan beberapa narasumber di kota-kota berbeda yang memiliki persepektif mengenai perjuangan hidup Salawati Daud sebagai tokoh pergerakan perempuan. Narasumber-narasumber yang dihadirkan dalam film memberikan data yang sesuai dengan tema film yang diusung.

Ika Mahardika telah menyusun pertanyaan-pertanyaan yang akan diajukan kepada narasumbernya, Sebelumnya, Ika Mahardika telah memiliki informasi mengenai Salawati Daud yang diperolehnya dari beberapa buku dan sebuah tesis. Informasi inilah yang menjadi bekal Ika Mahardika dalam menyusun pertanyaan-pertanyaan untuk narasumbernya.

Wawancara yang digunakan Ika Mahardika tersebut termasuk wawancara terstruktur dengan teknik purposive, dimana wawancara terstruktur merupakan wawancara yang terarah, di dalamnya susunan pertanyaan sudah ditentukan sebelumnya (Ratna, 2010). Teknik purpose memberi ketentuan bahwa peneliti sudah memiliki informasi awal, sebagai pemahaman kasar, sehingga ia dapat menunjuk orang tertentu yang dianggap dapat memberikan informasi (Ratna, 2010).

a) Wawancara Dias Pradadimara

Pada tanggal 15 April 2018 lka Mahardika menemui Dias Pradadimara untuk wawancara. Ternyata Dias Pradidmara banyak mengetahui tentang Salawati Daud, dan menjelaskan mengenai Salawati Daud secara runtut dan rinci. 


\section{CAPTURE}

Hasil yang diperoleh Ika Mahardika dari wawancara tersebut adalah informasi Salawati Daud memang merupakan tokoh yang luar biasa. Berawal Dias Pradadimara inilah akhirnya Ika Mahardika mengetahui bahwa pada peristiwa 1965 Salawati Daud dianggap atau dituding oleh tentara bertanggung jawab terhadap peristiwa tersebut, Salawati Daud ditangkap karena dianggap sebagai bagian dari PKI dan dimasukkan penjara Bukit Duri di Jakarta selama 13 tahun. Dias Pradadimara juga menjelaskan alasan mengapa saat ini sosok Salawati Daud dilupakan dan seakan-akan dihilangkan dari sejarah karena Salawati merupakan salah satu anggota dari GERWANI (Mahardika, 2019).

b) Wawancara Siti Maryam

Pada tanggal 16 April 2018, Shinta Febriany berangkat ke Yogyakarta dan melakukan wawancara dengan Siti Maryam yang merupakan salah satu alumni Universitas Gajah Mada. Siti Maryam telah menulis tesis tentang Salawati Daud yang berjudul Salawati Daud dan Gagasan tentang Persatuan Nasional Indonesia Sebuah Biografi Politik 1909-1985.

Hasil yang didapatkan Shinta Febrianty dari wawancara tersebut merupakan data Salawati Daud tentang karir jurnalistiknya, tulisan-tulisan yang dibuat oleh Salawati Daud tentang perempuan yang dimuat dalam surat kabar
Sulawesi Marhaen dan Pedomanguru. Salawati Daud telah aktif di jurnalistik pada tahun 1930-an, pikiran penting Salawati Daud tentang perempuan adalah hak, persamaan hak, terutama dalam kesadaran berbangsa, karena menurut Salwati Daud perempuan juga penting untuk aktif di dalamnya. Siti Maryam juga menjelaskan tentang keterlibatan Salawati Daud dalam kasus Kahar Muzakkar, bagaimana Salawati Daud menjadi mediasi antara Kahar Muzakkar dan pihak pemerintah saat itu. Pengalaman Salawati Daud yang menjadi koordinator perempuan dalam peristiwa Masamba Affair yang dimuat dalam koran, dan perjalanan Salawati Daud yang akhirnya membangun poliklinik Muhammadiyah untuk perempuan, bagaimana perjuangan Salawati Daud memperjuangkan hak-hak perempuan dan akhirnya bergabung dengan Gerakan Wanita Indonesia (GERWANI) (Mahardika, 2019). Hasil wawancara tersebut digunakan sebagai verifikasi data yang telah didapatkan dari studi pustaka.

c) Wawancara Paulus Julianto Salawati

Berangkat dari tesis yang ditulis oleh Siti Maryam, Ika Mahardika kemudian mencari kontak cucu dari Salawati Daud. Setelah mendapatkan kontak dan bertemu dengan cucu Salawati Daud bernama Paulus Julianto, Ika Mahardika mewawancarainya. Hasil yang didapatkan oleh Ika Mahardika dari wawancara 
tersebut berupa data pandanganpandangan Salawati Daud tentang perempuan-perempuan di Makassar, bagaimana Salawati Daud hampir merubah kebiasaan orang-orang Makassar mengenai pernikahan dini, karakter dan sifat dari Salawati Daud yang pemberani dan sederhana, kemudian juga cerita Salawati Daud ditahan selama 13 tahun penjara tanpa alasan dan proses lebih lanjut.

d) Wawancara Mujiati

Setelah wawancara selesai, Paulus Julianto menawarkan untuk mendatangi tempat yang paling sering dikunjungi Salawati Daud semasa hidupnya, salah satu panti jompo di Jakarta. Panti jompo tersebut merupakan tempat rekan-rekan Salawati Daud menetap. Salah satu rekan Salawati Daud yang bersedia melakukan wawancara adalah Mujiati.

Hasil yang ditemukan oleh lka Mahardika dan Shinta Febriany dari wawancara dengan Mujiati ini mengenai bagaimana Salawati Daud sangat disegani oleh orang-orang karena Salawati Daud merupakan orang yang pemberani, rendah hati, dan sederhana. Selain itu digambarkan bagaimana keseharian Salawati Daud semasa hidupnya, bagaimana Salawati Daud menghadapi masa-masa tahanan selama 13 tahun (Mahardika, 2019).

\section{4) Teknik Dokumen}

Teknik pengumpulan data dokumen biasanya digunakan untuk memperoleh informasi dari tangan kedua kecuali jika memang dokumen itu sendiri yang menjadi sasaran kajian yang berbentuk berbagai catatan baik resmi maupun catatan yang sangat pribadi dan mengandung kerahasiaan (Rohendi Rohidi, 2011). Ciri khas dokumen adalah menunjuk pada masa lampau, dengan fungsi utama sebagai catatan atau bukti suatu peristiwa, aktivitas, dan kejadian tertentu (Ratna, 2010).

Setelah mendapatkan informasi dari Siti Maryam mengenai tulisan-tulisan Salawati Daud, Shinta Febrianti mengunjungi Perpustakaan Nasional Yogyakarta pada tanggal 17 April 2018, Di sana Shinta Febriany menemukan tulisantulisan Salawati Daud di beberapa koran. Dokumen-dokumen ini kemudian ditampilkan ke dalam film dokumenter The Unremembered sebagai bukti penguat bahwa Salawati Daud pernah mengungkapkan gagasan-gagasannya tentang perempuan dan pengalamannya dalam kasus Kahar Muzakkar lewat tulisan-tulisannya yang diterbitkan di beberapa koran pada saat itu.

Pertemuannya dengan Paulus Julianto Salawati, Ika Mahardika mendapatkan foto-foto dan dokumendokumen tentang Salawati Daud diantaranya merupakan foto-foto Salawati Daud dan suaminya, foto-foto Salawati Daud dengan anggota-anggota DPR, 


\section{CAPTURE}

dokumen-dokumen mengenai sertifikat Bintang Maha Putera, Surat putusan anggota Dewan Perwakilan Rakyat (DPR) fraksi Partai Komunis Indonesia (PKI), surat perintah perubahan status penahanan, surat keterangan bepergian Salawati Daud (Mahardika, 2019).

\subsection{Cara Mengolah Data}

Cara mengolah data yang dilakukan Ika Mahardika dalam membuat film dokumenter The Unremembered dibagi menjadi beberapa tahap diantaranya sebagai berikut:

\section{1) Proses Seleksi Data}

Informasi/data yang diperoleh Ika Mahardika tidak semua disajikan dalam film namun diseleksi untuk mencari konten yang sesuai dengan konsep awal. Penyeleksian data ini dimulai dari penyeleksian narasumber dan data hasil wawancara. Dalam proses riset, Ika Mahardika mendapatkan 6 narasumber di antaranya adalah Dias Pradadimara, Siti Maryam, Paulus Julianto Salawati, Julius Sihombing, Mujiati, dan Yusuf Suherman. Kemudian dilakukan proses penyeleksian narasumber berdasarkan kapasitasnya dalam memberikan data.

Hasil seleksi narasumber yang dilakukan, Ika mengeliminasi dua narasumber yang akan ditampilkan dalam film yaitu Julius Sihombing dan Yusuf Suherman. Hal itu didasarkan atas data yang diberikan memiliki kesamaan dan keterbatasan informasi. Proses seleksi selanjutnya adalah seleksi hasil wawancara. Hasil wawancara diseleksi oleh Ika berdasarkan premis-premis umum dan hal-hal pokok terkait dengan Salawati Daud.

\section{2) Penyusunan Data}

Teknik penyusunan data yang digunakan Ika Mahardika dalam menuturkan film dokumenter The Unremembered menggunakan struktur kronologis. Struktur kronologis merupakan peristiwa yang dituturkan secara berurutan dari awal hingga akhir. Pada struktur ini, yang namanya waktu menentukan konstruksi, atau konstruksi alur kisah bergantung pada waktu. Struktur ini menggunakan teknik kilas-balik, maka susunan adengan akan mengikuti perjalanan waktu (Ayawalia, 2008).

Ika Mahardika merasa penuturan cerita kronologis sangat tepat digunakan dalam pembuatan film yang berkaitan dengan sejarah, selain karena terstruktur, penuturan kronologis ini juga menurutnya lebih mudah untuk dirancang.

Film dokumenter The Unremembered tergolong ke dalam dokumenter biografi, dengan menceritakan secara singkat asal usul Salawati Daud berikut riwayat pendidikannya, kemudian beralih ke karir dan perjuangannya terhadap persamaan hak perempuan hingga tentang kehidupan politisnya. Berikut ini adalah penuturan cerita film The Unremembered: 
a. Menceritakan secara singkat asal usul Salawati Daud berikut riwayat pendidikannya.

b. Menceritakan secara singkat aktivitas Salawati Daud sebagaijurnalistik.

c. Menceritakan secara singkat mengenai perjuangan Salawati Daud tentang persamaan hak perempuan.

d. Menceritakan secara singkat tentang bagaimana Salawati Daud bergabung dengan Gerakan Wanita Indonesia (GERWANI).

e. Menceritakan secara singkat tentang kehidupan politik Salawati Daud.

f. Menceritakan secara singkat peran Salawati Daud dalam peristiwa Masamba Affair.

g. Memaparkan alasan mengapa Salawati Daud dihilangkan dari sejarah.

\section{3) Strategi Visual}

Ika Mahardika menciptakan visualisasi dalam film dokumenter The Unremembered dengan cara memadukan beberapa foto yang sudah melalui proses editing terlebih dahulu. Visualisasi bertujuan untuk menciptakan gambaran keadaan Salawati Daud di masa lampau, sehingga hasil visualisasi tidak selalu menggambarkan keadaan Salawati Daud sesungguhnya di masa itu. Selain itu, film ini juga memuat footage-footage yang berhubungan dengan Salawati Daud, seperti monumen peringatan Masamba Affair di Masamba dan tempat-tempat yang berkaitan dengan SalawatiDaud.

\subsection{Teknik Pembuatan Treatment}

Langkah paling awal yang dilakukan adalah menjelajahi internet, membaca jurnal-jurnal mengenai sosok Salawati Daud dan berbagai sumber yang salah satunya adalah tesis yang ditulis oleh ibu Siti Maryam. Tesis tersebut merupakan hasil penelitian mengenai Salawati Daud mulai dari latar belakang keluarganya hingga perjalanannya pada masa itu.

Data yang terkumpul kemudian disaring, dan pembahasannya difokuskan kepada kisah hidup dan perjuangan Salawati Daud dalam menyeratakan hak perempuan, menggagas persatuan Indonesia melalui profesinya sebagai guru, walikotam dan jurnalis. Kemudian dilakukan penulisan storyline. Setelah bertemu dan melakukan wawancara dengan akademisi Sejarah, Dias Pradadimara, yang juga menjadi narasumber utama dalam film ini, selanjutnya Ika Mahardika mengembangkan storyline tersebut menjadi treatment dengan memperhatikan pemahaman dengan tema yang diangkat.

Treatment atau storyline merupakan sketsa yang dapat memberikan gambaran pendekatan dan keseluruhan isi cerita. Treatment mutlak diperlukan bagi dokumenter, meskipun tak ada yang baku dalam penulisan bentuk atau gaya treatment (Ayawalia, 2008).

Prinsip struktur dalam metode penulisan naskah tidak perlu dijadikan 


\section{CAPTURE}

aturan baku, tetapi lebih digunakan sebagai alat bantu yang berfungsi untuk menjelaskan apa dan bagaimana film tersebut akan disampaikan atau diceritakan (Ayawalia, 2008). Dalam film The Unremembered ini, Ika Mahardika dan Shinta Febriany melakukan metode dengan sistem revisi dalam menulis treatment atau naskah, hal tersebut dilakukan karena data-data mengenai Salawati Daud bergantung pada informasi baru yang terus berkembang. Oleh karena itu, penulisan treatment ini melakukan sistem revisi.

\section{SIMPULAN}

Film The Unremembered merupakan film dokumenter yang langkah pembuatannya membutuhkan proses kreatif sutradara melalui tahapan praproduksi. Seorang sutradara harus mampu menciptakan inovasi dan gagasan baru. Ika Mahardika selaku sutradara memiliki formula tersendiri dalam pembuatan filmnya. Ika Mahardika mengerjakan tahapan praproduksi beriringan dengan tahapan produksi. Ika Mahardika mempertimbangkan momenmomen yang sedang berlangsung pada saat proses pencarian data atau riset.

Premis pokok yang ingin disampaikan sutradara bisa dilihat dari dan hal yang paling ditonjolkan dalam film The Unremembered yaitu memberikan kesadaran nasionalisme melalui tokoh Salawati Daud. Salawati Daud adalah salah satu tokoh pergerakan nasional, seorang emansipasi perempuan yang selalu memperjuangkan hak-hak perempuan untuk tampil di ruang-ruang publik pada masa kolonial, seorang tokoh revolusioner, tokoh yang memberikan sumbangsih tenaga, pikiran dalam merebut dan mempertahankan kemerdekaan Indonesia.

Hasil analisis dan pembahasan proses kreatif Ika Mahardika selaku sutradara dalam pembuatan film dokumenter The Unremembered dapat disimpulan sebagai berikut :

a. Proses penemuan ide dalam film The Unremembered didasarkan pada pertemuan Ika Mahardika dengan Shinta Febriany selaku produser dalam film dokumenter The Unremembered.

b. Proses penemuan ide dalam film The Unremembered didasarkan pada ketertarikan Ika Mahardika terhadap isu-isu perempuan tentang kesetaraan hak.

c. Kreativitas Ika Mahardika dalam menggunakan bentuk biografi atau potret dengan gaya ekspositoris dalam menyajikan film dokumenter The Unremembered.

d. Kreativitas sutradara Ika Mahardika dalam menggali data tentang Salawati Daud terletak pada kemampuan penggunaan metode riset etnografi.

e. Ika Mahardika selaku sutradara dalam film The Unremembered mampu 
menggunakan metode etnografi secara runtut dimulai dari penelusuran literatur, observasi lapangan, wawancara dan dokumen.

f. Kreativitas dalam mengolah teknikteknik etnografi seperti studi literatur, teknik observasi terkendali, wawancara mendalam dan teknik dokumen sehingga film ini mampu menampilkan data yang kuat dan valid tentang Salawati Daud.

g. Kreativitas Ika Mahardika dalam mengolah data mulai dari penyeleksian data dengan pertimbangan kapasitas informasi yang diberikan dan bagaimana data itu kemudian ditampilkan secara kronologis.

h. Kreativitas Ika Mahardika dalam mengkolaborasikan data yang didapatkan melalui narasi, foto, dan footage untuk membangun alur cerita yang kuat.

Proses penulisan treatment film The Unremembered yang dilakukan oleh lka Mahardika dan Shinta Febriany termasuk sistem revisi, karena data-data mengenai Salawati Daud bergantung pada informasi baru yang terus berkembang.

\section{DAFTAR ACUAN}

Afrianto, D. T. (2019). The Phenomenon of Urban Culture in Film Dendang Bantilang. International Journal of Visual and Performing Arts, 1(1).

Ayawalia, G. R. (2008). Dokumenter: Dari Ide Sampai Produksi. Jakarta: Fakultas Film dan Televisi, IKJ.
Candra D.A., N. R., A. (2013). Bentuk dan Gaya Penuturan Film Dokumenter Berbasis Budaya Daerah PB XII: Berjuang untuk Sebuah Eksistensi. CAPTURE: Jurnal Seni Media Rekam, 5(1), 57-72.

Febrianty, S. (2019). Produser film The Unremembered (wawancara).

Mahardika, I. (2019). Sutradara film The Unremembered (wawancara).

Ratna, N. K. (2010). Metode Penelitian: Kajian Budaya dan IImu Sosial Humaniora pada Umumnya. Yogyakarta: Pustaka Pelajar.

Rohendi Rohidi, T. (2011). Metodologi Penelitian Seni. Semarang: Cipta PrimaNusantara. 